\section{Best, Charles Herbert}

W. Hubl

Ehem. Institut für Klinische Chemie und Labormedizin, Krankenhaus Dresden-Friedrichstadt, Dresden, Deutschland

Lebensdaten Geboren 27. Februar 1899 in West Pembroke (Main, USA), gestorben 31. März 1978 in Toronto. Medizinstudium in Toronto ab 1916 mit den Schwerpunkten Physiologie und Biochemie; ab 1921 gemeinsam mit Frederick Banting Isolierung von Pankreasextrakten zur Behandlung von Diabetes mellitus; 1923 industrielle Herstellung von Bauchspeicheldrüsenextrakten von Rindern; 1929 Professur an der Universität von Toronto; 1941 Direktor des BantingBest-Institutes; Spezialgebiete Muskel- und Sportphysiologie.

Verdienste Gemeinsam mit Banting Entdecker des Insulins. Als Banting 1923 gemeinsam mit John James Richard MacLeod den Nobelpreis für Medizin für die Entdeckung des Insulins erhielt, teilte er das Preisgeld mit Charles Best.

\section{Literatur}

Eckart WU, Gradmann C (2006) Ärzte Lexikon - Von der Antike bis zur Gegenwart, 3. Aufl. Springer, Berlin/Heidelberg/New York 